\title{
Retracted: Cardiac Arrest following a Myocardial Infarction in a Child Treated with Methylphenidate
}

\author{
Case Reports in Pediatrics
}

Received 5 November 2020; Accepted 5 November 2020; Published 10 February 2021

Copyright (c) 2021 Case Reports in Pediatrics. This is an open access article distributed under the Creative Commons Attribution License, which permits unrestricted use, distribution, and reproduction in any medium, provided the original work is properly cited.

In the article titled "Cardiac Arrest following a Myocardial Infarction in a Child Treated with Methylphenidate" [1], the authors have re-evaluated the case in response to concerns that the conclusion that methylphenidate can cause cardiac arrest in otherwise healthy children was not supported. Since the publication of the article, the child passed away. The results of a genetic cardiomyopathy testing panel showed a lamin $\mathrm{A} / \mathrm{C}$ mutation (heterozygote). With this knowledge, it is possible that the child suffered from cardiomyopathy rather than a remote myocardial infarction as suggested. The article is therefore being retracted with the agreement of the authors and the editorial board.

\section{References}

[1] K. Munk, L. Gormsen, W. Y. Kim, and N. H. Anderson, "Cardiac Arrest following a Myocardial Infarction in a Child Treated with Methylphenidate," Case Reports in Pediatrics, vol. 2015, Article ID 905097, 4 pages, 2015. 